\title{
Cuestionando consensos: algunos apuntes frente al - ¿eventual? - ascenso de los BRICS como poderes globales
}

JAVIER GARAY*

Artículo recibido: 18 de abril de 2017

Artículo aceptado: 26 de septiembre de 2017

Doi: http://dx.doi.org/10.12804/revistas.urosario.edu.co/desafios/a.5578

Para citar este artículo: Garay, J. (2018). Cuestionando consensos: algunos apuntes frente al — ¿eventual? — ascenso de los BRICs como poderes globales. Desafíos, 30(2), 237-278. Doi: http://dx.doi.org/10.12804/revistas.urosario.edu.co/desafios/a.5578

\section{Resumen}

El presente articulo es una invitación a la reflexión. En los estudios internacionales, damos por sentadas muchas realidades que, ante el escrutinio de reflexiones teóricas y la aplicación de metodologias de investigación — como los modelos con premisas importadas de la economía y la teoría de juegos—, pueden poner en duda esas conclusiones o llevarnos a plantear nuevos escenarios. El ejercicio se hace, en este caso, a propósito de lo que se ba denominado el ascenso de los BRICS y las expectativas que este ha generado. Palabras clave: metodología, teoría de juegos, BRICS, China, poder.

\footnotetext{
* Doctor en Ciencia Política de la Universidad Paris-Est Marne la Vallée. Magíster en Asuntos Internacionales y profesional en Gobierno y Relaciones Internacionales de la Universidad Externado de Colombia. Docente, investigador de la Facultad de Finanzas, Gobierno y Relaciones Internacionales de la Universidad Externado de Colombia, Bogotá, Colombia. Correo electrónico: javier.garay@uexternado.edu.co. ORCID: http://orcid. org/0000-0002-6218-957X
} 


\title{
Questioning Consensus: Some Notes on the -Eventual?- Rise of the BRICS as Global Powers
}

\begin{abstract}
This article is meant to encourage a deeper reflection within the academic study of international relations (IR) in Latin America. In the discipline of IR, there are several, broadly accepted conclusions but when contrasted with theoretical advances and/or some methodologies - such as economic models and game theory - must at least be discussed. The analysis presented here deals with the conclusions regarding the eventual ascent of the BRICS countries.
\end{abstract}

Keywords: methodology, game theory, BRICS, China, power.

\section{Questionando consensos: alguns apontamentos frente à - ¿eventual? - ascensão dos BRICs como poderes globais}

\begin{abstract}
Resumo
O presente artigo é um convite á reflexão. Nos estudos internacionais damos por certas muitas realidades que, ante o escrutinio de reflexões teóricas e a aplicação de metodologias de pesquisa, como os modelos com premissas importadas da economia e a teoria de jogos, podem pôr em dúvida essas conclusões ou levar-nos a conceber novos cenários. O exercício se faz, neste caso, a propósito do que se tem denominado a ascensão dos BRICS e as expectativas que ele tem gerado.
\end{abstract}

Palavras-chave: metodologia, teoria de jogos, BRICS, China, Poder

\section{Introducción}

El ascenso de potencias globales que remplacen a Estados Unidos o, siquiera, que limiten su accionar ha sido uno de los temas centrales de 
los análisis ${ }^{1}$ internacionales por lo menos desde la década de los noventa. En particular, desde lo que fue percibido como el predominio de una estrategia unilateral durante los gobiernos de George W. Bush (20012009), se dio por sentada la necesidad de una menor concentración del poder en el sistema internacional. Hoy, se retoma con la llegada al poder de Donald Trump y las expectativas negativas que sus propuestas, en materia de política exterior, han generado en relación con el poder estadounidense y el vacío consecuente.

Tal vez por ello, el acelerado crecimiento económico de China - $\mathrm{y}$ su mayor presencia en el escenario global- junto con el fortalecimiento, en diversos ámbitos — y en menor medida—, de países como Brasil, Rusia, India y, más recientemente, Sudáfrica, despertaron una suerte de esperanza entre algunos analistas sobre un futuro de carácter multilateral en el ámbito global. Si bien esos no forman parte del mainstream de la disciplina de las relaciones internacionales ni necesariamente representan la posición mayoritaria dentro de esta, sí son representativos de una aproximación relevante en al abordaje de los temas internacionales en América Latina².

Este optimismo, esta esperanza, en el fondo, se explica como resultado de un proceso de pensamiento lógico, pero no por ello simplista: si el unilateralismo generó tantos fenómenos percibidos como negativos, su completa oposición, el multilateralismo, debe generar mayores beneficios.

\footnotetext{
1 En este escrito se utilizará de manera intencional el término “análisis" para referirse a los escritos que tratan temas de asuntos internacionales pero que no necesariamente son reflejo de procesos de investigación o de reflexiones académicas. La palabra "estudios" se utilizará para referirse precisamente a ese tipo de contribuciones. Los análisis reflejan las opiniones, posiciones y emociones de los autores aunque carezcan de sustento académico y de rigurosidad científica. El problema es que los análisis tienen mayor difusión que los estudios. No obstante, debería estudiarse si en realidad existe una gran brecha entre unos y otros y reflexionar sobre sus conclusiones y los métodos de investigación utilizados.

2 Podría pensarse que no se circunscribe a América Latina sino que representa la visión en los países "del Sur", pero esto tendría que probarse con un estudio sobre publicaciones.
} 
Así, se concibe que un sistema de carácter multilateral es superior en sus beneficios a uno unipolar. Extrapolando el análisis de lo internacional al pensamiento económico, en efecto, se podría señalar que la competencia tiene ventajas superiores, en sus efectos, a los generados por el monopolio o el oligopolio. Los precios son más bajos, hay interés por mejorar la calidad y existen alternativas para diferentes gustos.

No obstante, la extrapolación no puede darse de manera automática, mucho menos de manera simplista. Los estudios de relaciones internacionales han desarrollado un buen número de perspectivas teóricas y de contribuciones analíticas y metodológicas que deben tenerse en cuenta para sacar este tipo de conclusiones. Al fin y al cabo, la discusión está planteada como un resultado futuro, aún no verificado y, por lo tanto, no puede darse por hecho que las realidades observadas - y percibidas — hoy se perpetúen hacia el futuro.

En este artículo se mencionarán algunos de esos elementos y se utilizarán como aspectos a tener en cuenta en los estudios sobre los impactos que, en el futuro, puede tener el ascenso de países como los mencionados. Este escrito busca demostrar que el ascenso de los BRICS no necesariamente generará un mejor sistema internacional frente a uno predominantemente unipolar.

Para demostrar la anterior afirmación, el artículo está dividido en las siguientes partes. En la primera, se hará una demostración de por qué los BRICS pueden considerarse potencias en ascenso a pesar de que la mayoría de esos países se encuentra en problemas desde hace algunos años y esto se integrará con una caracterización de los países que conforman el acrónimo. De esta manera se resaltan las contradicciones y complementariedades empíricas del concepto de poder y se resaltan algunos desafíos del método para demostrarlas. La segunda parte se compondrá de varios apartados en los que se aportarán algunos elementos teóricos y metodológicos de las relaciones internacionales para tener en cuenta en el momento de evaluar las implicaciones del ascenso de los países mencionados. 
Estos apartados surgen de la reflexión sobre cuáles pueden ser los criterios que determinen la superioridad o inferioridad de cualquier distribución de poder en el ámbito internacional. De la revisión de la literatura y del análisis de algunos de los textos optimistas sobre el ascenso de los BRICS, se han rescatado cuatro criterios ${ }^{3}$. Primero, la generación de condiciones para un sistema internacional más pacífico. Segundo, las implicaciones para un sistema internacional más justo. Tercero, los efectos sobre un sistema internacional más incluyente. Cuarto, la consecución de un sistema internacional más estable. En cada apartado se hará una discusión sobre la definición de cada uno de esos criterios.

Los elementos a tener en cuenta se identificaron en la evolución y los debates teóricos en relaciones internacionales. No obstante, al requerirse un fuerte componente prospectivo en un estudio sobre las posibles (futuribles) implicaciones de algo que no ha sucedido, no se puede emplear cualquier método de aplicación de las teorías. Los estudios de caso y los análisis numéricos (series de tiempo, estadísticas y demás) resultan insuficientes puesto que, como se mencionó antes, no se puede asumir que una trayectoria hoy se mantenga en el futuro. Lo mismo sucede con la historia. No se pueden anticipar los procesos futuros teniendo como único dato el conocimiento de la historia del actor, por más información que se haya recabado.

Por lo anterior, el método que mejor se adapta —y que más aportes genera- al estudio que acá se pretende es el de los modelos aplicados a las relaciones internacionales y provenientes del pensamiento y de la formalización en economía. A través de los modelos constituidos, se pueden establecer diferentes condiciones para obtener uno u otro resultado y se pueden evidenciar los múltiples requerimientos para demostrar que no es automático y, en algunos casos, poco probable

\footnotetext{
3 La literatura revisada se limitó a fuentes latinoamericanas y no se hizo con un método sistemático. En las principales publicaciones periódicas de Brasil y Colombia se miraron los artículos publicados sobre los BRIC y se observaron las hipótesis y la visión de los autores respecto del ascenso.
} 
que un sistema multipolar, liderado por los BRICS, sea superior al que existe hoy en día.

¿Se puede extrapolar directamente los resultados de, por ejemplo, la teoría microeconómica al análisis de los temas internacionales? Pueden existir motivaciones diferentes de la acción en la política internacional. Sin embargo, esto no impide aplicar los hallazgos que, para explicar la decisión de los actores, se han hecho en la ciencia económica. Primero, porque aunque dicha aplicación se haya realizado para temas relacionados con decisiones económicas, el conocimiento hace referencia a las motivaciones, incentivos, restricciones y demás de la toma de decisiones de los individuos. En este sentido, la imposibilidad de aplicar estos conocimientos requeriría demostrar que el ser humano adopta procesos de toma de decisiones diferentes según actúe en una dimensión económica o política.

Segundo, porque como se señaló antes, la discusión de este escrito es de carácter prospectivo y, por lo tanto, hipotético. Para ello, es necesario contar con herramientas atemporales que permitan explicar el comportamiento (la decisión) según el contexto. Como la disciplina de las relaciones internacionales no cuenta con modelos desarrollados de este tipo, se pueden utilizar los de ciencias sociales que sí los hayan desarrollado. Este es el caso de la ciencia económica.

Tercero, porque como se señalará en cada apartado, existen características semejantes entre el carácter de potencias y el carácter de empresas representativas en un mercado que permiten, dentro de ciertos supuestos, asumir implicaciones para el contexto. Este fue el método usado por Waltz (1979) para desarrollar su propuesta teórica.

A pesar de estos y otros argumentos, debe quedar claro que la aplicación del modelo solo debe entenderse en el sentido de la toma de decisión y, en consecuencia, de la acción ${ }^{4}$ de los agentes. Esto no requiere de otros

\footnotetext{
4 En curso el autor de este escrito está desarrollando una investigación en la que indaga
} sobre los posibles aportes de la Escuela Austriaca de Economía a los vacíos teóricos de 
supuestos como el de entender que los Estados sean iguales que las empresas ni que el mercado sea igual a la política internacional.

En el último apartado, se proveen unas conclusiones que surgen del análisis y que abren la puerta a futuras investigaciones.

\section{Los BRICS como potencias en ascenso}

Algunos análisis internacionales han dado por hecho que es superior un sistema multipolar a uno unipolar. De manera específica, la discusión ha estado ilustrada por el ascenso percibido de los denominados BRICS (Brasil, Rusia, India, China y Sudáfrica).

Si bien el ascenso de un sistema internacional de ese tipo puede ser una buena noticia, el dar por sentada su superioridad es olvidar los aportes de diferentes autores de las relaciones internacionales que demostraron que otros tipos de distribuciones de poder eran deseables. Para Waltz (1979), por ejemplo, la distribución ideal era una de carácter bipolar. Otros autores, agrupados en la que se denominó la teoría de la estabilidad hegemónica, consideran que el sistema internacional ideal es uno de carácter unipolar (Pahre, 1999).

Antes de profundizar en la discusión en torno de estas posiciones, se debe establecer si los países agrupados en la sigla BRICS pueden ser considerados poderes en ascenso. ¿De qué tipo de poder se está hablando? ¿Su poder se está fortaleciendo?

Este tipo de preguntas, aunque necesarias, han sido obviadas de manera tradicional cuando de establecer el ascenso de ciertos poderes se trata. En el caso de los BRICs es importante abordarlas por, al menos, dos razones. Primero, porque en el pasado se asumió el escalamiento por la coyuntura de un crecimiento económico acelerado en esos países y sus potenciales crecimientos futuros. Segundo, porque en la actualidad 
las tasas de crecimiento extraordinarias han terminado y, al contrario, la mayoría de estos países se encuentra en una situación difícil en el plano económico.

Brasil atraviesa una situación de recesión económica y de descrédito político marcado por escándalos de corrupción, la destitución de su presidenta, Dilma Rousseff, y los problemas de gobernabilidad de su remplazo, el presidente Michel Temer. Rusia, desde hace varios años, vio disminuidas sus tasas de crecimiento y en la actualidad se ha visto fuertemente afectada por la caída en los precios del petróleo. Aunque no se pueda hablar de una crisis de gobernabilidad, cuenta con un régimen cada vez más autoritario en el poder, representado en la figura del presidente Vladimir Putin. India no ha presentado las mismas tasas de crecimiento acelerado que China, pero sí ha tenido una senda de crecimiento sostenido desde los años noventa. No obstante, este crecimiento no se configura como determinante en su conversión como potencia global. Sudáfrica es el país que se incluyó en el acrónimo más recientemente: sus tasas de crecimiento no son importantes y cuenta con problemas sociales y políticos, pero su importancia relativa en el continente africano se ha consolidado en los años recientes. En el caso de China, las tasas de crecimiento, aunque no demuestran una recesión, sí se han visto disminuidas por procesos internos que algunos analistas sugieren se deben a un problema de endeudamiento público excesivo, a una burbuja inmobiliaria o a cambios demográficos (Youwei, 2015; Chen, 2015; Leung, 2015).

Así las cosas, ¿qué se puede decir sobre el poder de estos países? Si se observa detenidamente tanto el optimismo de la década de los años dos mil como el pesimismo de años recientes, ambos descansan sobre frágiles presunciones. El que un país crezca por algunos años y tenga unos indicadores promisorios sobre el futuro no implica que la senda de crecimiento se sostenga hacia el futuro. Lo mismo sucede en caso de crisis económica o de disminución en las tasas de crecimiento. En ese caso, se deben analizar las causas del crecimiento y su potencial de sostenimiento futuro, si de hacer análisis económico se trata. 
Lo mismo se puede sostener de los demás indicadores que se consideran representativos del ascenso en el poder de los países en el plano internacional. Los datos no se pueden tomar de manera independiente de un análisis más profundo y, a su vez, no se puede asumir que los datos actuales se sostendrán en el largo plazo. Esta aproximación desconoce la importancia de la incertidumbre frente al futuro y, por lo tanto, las más de las veces está destinada a estar equivocada, ser inexacta o irrelevante.

Hacer tal análisis sobre los "fundamentales" del proceso de crecimiento económico y de desarrollo de estos países está por fuera del objeto de estudio de este escrito. No obstante, un abordaje sobre el proceso de consolidación y de proyección de poder en el ámbito internacional no requiere de tal análisis. Menos en las características actuales de dicho ámbito.

El concepto de poder internacional ha sufrido una transformación en los años recientes como lo demuestran los aportes consignados en trabajos editados por, entre otros, Finnemore y Goldstein (2013). De una concepción meramente material en la que se consideraba que el poder estaba representado por criterios objetivos - y medibles - se pasa al reconocimiento del poder desde un punto de vista ideacional, identitario o basado en la construcción intersubjetiva, por parte de los actores externos al actor, considerado como poderoso. El poder ha penetrado ámbitos como los de la autoridad (Lake, 2013), el reconocimiento exterior e incluso la capacidad de subordinar algunos actores con criterios objetivos que no se pensaban generadores de poder en las políticas de acción internacional de países tradicionalmente considerados como poderosos (Katzenstein, 2013; Stein, 2013).

Desde esta aproximación, si bien el fortalecimiento económico de los países BRICS se ha visto menguado en los últimos años como resultado de sus problemas internos, se puede asumir que estos países están en un inexorable proceso de convertirse en poderes mundiales porque son vistos como tales. Los cinco países incluidos en el acrónimo son, indiscutiblemente, potencias regionales. Pero, además, se les ha dado importancia a sus posiciones y decisiones en el ámbito global. Pueden ser países no desarrollados o con problemas domésticos, pero en el 
imaginario colectivo global se toman por poderes internacionales, en ascenso o ya consolidados.

Una demostración rigurosa de la construcción de identidad es compleja. De hecho, a pesar de que el concepto existe y es utilizado por los académicos de la disciplina de relaciones internacionales, aún no existen propuestas que permitan demostrar este concepto. ¿Cuáles son los criterios? ¿Cómo se pueden medir? ¿Qué metodologías se pueden utilizar? Una aproximación válida podría ser la de indagar en diferentes expresiones de la política internacional (esto es, discursos, análisis, noticias, entre otros) el lenguaje que se utiliza para referirse a diferentes actores y establecer así la identidad que estos han creado o que los demás han creado para ellos. No obstante, esta metodología resulta muy ambiciosa para este escrito.

Por ello, aunque se reconocen sus limitaciones, se optó por consultar la base de datos del Pew Research Center (2015) para indagar sobre cómo son percibidos por las personas encuestadas ${ }^{5}$ los diferentes países BRICS. Aunque hubiera sido deseable contar con la percepción acerca de todos y cada uno de los países que conforman el acrónimo, ninguna encuestadora pregunta por países diferentes a China y Rusia. En consecuencia, los datos a continuación descritos solo hacen referencia a estos dos países.

Ante la pregunta de cuál se estima es la potencia económica global para el año de la encuesta (2015), de cuarenta países, ocho consideran en una proporción mayor al $40 \%$ de los encuestados que la potencia es China. Dentro de ellos se encuentran Australia (57\%), Francia (49\%), Jordania (47\%), Canadá (46\%), España (44\%), Líbano (44\%), Italia (42\%) y Reino Unido (41\%). Si se compara a los países

\footnotetext{
5 Los encuestados son ciudadanos de los países incluidos en las encuestas. Esto significa que es muy probable que no sean ellos los que determinen la acción internacional de sus países. Esto puede plantear una debilidad en la demostración de la identidad construida, puesto que sería ideal contar con la visión que los practicantes y expertos de la política internacional tienen frente a los países BRICS. No obstante, también puede ser una fortaleza porque la visión de los ciudadanos promedio puede reflejar las ideas entronizadas, las más difundidas, sobre cómo se ve al otro.
} 
en donde más del $40 \%$ de los encuestados señaló que la potencia económica es Estados Unidos, China aún no se considera mayoritariamente una potencia. No obstante, si la comparación se hace frente a Japón, definitivamente se debe concluir que China es vista como una potencia hegemónica. En el caso del país nipón, en ninguno de los países donde se hace la encuesta la respuesta que favorece a este país supera el $16 \%$ (dada por los indonesios). Algo similar sucede con la Unión Europea: en ningún país su mención supera el $25 \%$ de los encuestados (guarismo obtenido en Alemania).

Un elemento interesante, que servirá para plantear interrogantes más adelante en este escrito, se encuentra en la visión que se presenta en lo que podría denominarse intra-BRICS. De los países encuestados, donde menos se considera que China es la potencia económica es India (10 \%). En Brasil, el guarismo se ubica en el $17 \%$, en Sudáfrica en el $21 \%$ y en Rusia en el $37 \%$. Es decir, los ciudadanos de los demás países estimados potencias en ascenso parecen no creer mucho en el ascenso del que muchos autores han considerado la potencia del futuro: China. En este mismo país, los ciudadanos parecen aún no creerse una potencia económica. Tan solo el $34 \%$ de los encuestados así lo piensa.

En otra pregunta se indaga sobre el reemplazo de Estados Unidos como superpotencia global. En ocho de los cuarenta países en donde se tomó la muestra, en una proporción mayor al $40 \%$ se espera que, eventualmente, China reemplazará a Estados Unidos. En donde más se cree esto es en la misma China y en Australia ( $54 \%$ en ambos casos). En ningún país hay una proporción mayor al $26 \%$ (Italia) que considere que China ya desplazó a Estados Unidos. Sorprende que en trece de cuarenta países una proporción superior al $40 \%$ de los encuestados considera que el reemplazo nunca se dará. Cuando se observan quiénes lo consideran de esta manera, la sorpresa pasa a ser menor y, al contrario, a ser más comprensible.

Los ciudadanos que menos creen (¿esperan?) que China sea la próxima superpotencia se encuentran en países vecinos y rivales de China: Japón (77\%), Vietnam (67\%), Filipinas (65\%), Corea del Sur (40\%) 
e Indonesia (40\%). Una segunda categoría está conformada por los ciudadanos estadounidenses (48\%) y sus aliados cercanos, Canadá (40\%) y México (43\%). En tercer lugar, están los ciudadanos de una de las potencias en ascenso: Brasil (56\%). Los cuatro países restantes en los que menos se cree que China algún día remplazará a Estados Unidos son casos cuya explicación no es tan clara, pero que no pueden estudiarse en este documento: Uganda (46\%), Líbano (44\%), Kenya (44\%) y Jordania (43\%).

Otra cuestión que podría sugerir un poder ascendente ${ }^{6}$ es la de la imagen que se tiene de un país en el ámbito internacional. Por ejemplo, ante esta pregunta, Estados Unidos tiene una imagen positiva superior al $40 \%$ de los encuestados en todos los países donde se realizó la encuesta (cuarenta) menos en seis países (Líbano, Turquía, Palestina, Irak, Rusia y Jordania ${ }^{7}$ ). China tiene una imagen positiva en treinta y tres de los cuarenta países de la encuesta. Los siete países que tienen una imagen positiva inferior al $40 \%$ son Canadá, Estados Unidos, Alemania, Jordania, Vietnam, Turquía y Japón. La menor proporción de imagen positiva de China se presenta en este último país con un $9 \%$. En esta pregunta se incluye otro de los BRICs: Rusia. Aquí, los únicos países que tienen una imagen positiva superior al $40 \%$ de los encuestados son Rusia, Vietnam, Ghana, China, Corea del Sur, Filipinas, Líbano e India. Los demás países tienen imágenes positivas inferiores a ese $40 \%$.

Así las cosas, existe una incipiente evidencia para afirmar que los países que conforman los BRICS se pueden considerar poderes en ascenso porque así lo creen lo demás actores. Aquellos que observan este ascenso como positivo encuentran diferentes razones para

\footnotetext{
6 De las elegidas, esta puede ser la pregunta que menos capacidad demostrativa tiene. No porque un país sea percibido de manera positiva demuestra que ese país sea poderoso. Incluso, si se considera que el poder está determinado por factores ideacionales o de autoridad, habría que demostrar, en un primer lugar, la relación entre buena imagen y autoridad desde un punto de vista teórico, analítico y empírico.

7 Interesantes los casos de Líbano y Jordania. Los encuestados consideran, en una gran proporción, que China no podrá reemplazar a Estados Unidos como superpotencia y, a su vez, tienen una mala imagen de este último país.
} 
explicar la importancia de estos países como potencias. Primero, se asume que estos países pueden limitar lo que se percibe como imperialismo estadounidense. Segundo, se considera que son una fuente de alternativas a las estructuras organizacionales e institucionales occidentales de después de la segunda posguerra. Tercero, algunos señalan el carácter más enfocado en la cooperación internacional, la transferencia de recursos y la diplomacia que la aproximación, considerada occidental, en general, y estadounidense, en particular, de la vía armada y de intervención.

Sin embargo, como se planteó en la introducción, estos beneficios no necesariamente surgen de manera automática por el ascenso de nuevas potencias. Esto se debe a que el poder, aunque ha sido abordado como neutral en la mayoría de estudios internacionales, no lo es. El poder no es un concepto independiente de quién lo detenta. Algunos autores han demostrado que quien sea la potencia, según sus realidades, prácticas, valores y demás, tendrá implicaciones en los impactos de la proyección de ese poder (Ruggie, 1992, p. 585; Pahre, 1999).

En efecto, así como el ascenso al poder puede concebirse como un proceso en el que resulta determinante la construcción de una identidad sustentada en ideas específicas frente al actor considerado poderoso, sus ideas — su concepción del mundo, los principios bajo los que se rige y su identidad corporativa, esto es, cómo se ve a sí mismo - resultan relevantes en la forma como hará uso de los elementos que implican poder.

No es automático que un mundo multipolar sea superior a uno unipolar si no se tienen en cuenta a quienes lo conforman. De esta manera, se podría sostener que existen muchos elementos que deben considerarse antes de afirmar que un mundo liderado por el ascenso de nuevas potencia, en particular de los BRICS, vaya a ser mejor que uno liderado por Estados Unidos o por Occidente.

Debido a la importancia de conocer al actor poderoso, a continuación se propone una forma de caracterizar a los países que conforman el acrónimo BRICS. Posteriormente, se hará una reflexión sobre cuáles 
criterios pueden incluirse para determinar si un sistema internacional es mejor que otro, su relación con la realidad de los BRICS y sus comportamientos a través del uso de los modelos mencionados en la introducción.

\section{¿Quiénes son los BRICS?}

Es importante quién detenta el poder en el ámbito internacional. Por ello, es primordial, si se considera que los BRICS son potencias en ascenso, caracterizar a estos países para dotar de contenido las presunciones que se hagan sobre su eventual uso del poder.

De manera general, los países BRICS se pueden caracterizar como poderes antihegemónicos en proceso de desarrollo. Por antihegemónicos se pretende señalar su interés por limitar, reducir o contrarrestar el papel de Estados Unidos en el ámbito internacional. De hecho, podría afirmarse que los países BRICs buscan ser una alternativa, no solo al poder de Estados Unidos, sino al predominio de los valores y lógicas occidentales. A pesar de tener este interés y de ser considerados, como acá se hace, potencias, estos países aún están en proceso de desarrollo. Ninguno de ellos cuenta con un acervo de riqueza suficiente para demostrar altos niveles de vida de sus poblaciones, del tamaño del mercado, del nivel de productividad económica, entre muchos otros indicadores.

Estos dos hechos generan una serie de dualidades en el comportamiento internacional de estos actores que dificultan el proceso de estudio. Se mencionan dos. Por un lado, estos países son fuertes críticos de las actuales condiciones internacionales, pero juegan bajo las normas (instituciones) y dentro de las organizaciones dispuestas para ello. Por el otro, como resultado de lo anterior, son países en los que existe una brecha constante entre el discurso político en escenarios internacionales y la práctica.

En la primera dualidad, se pueden mencionar diferentes casos. Brasil, durante el gobierno de Luiz Inacio Lula da Silva, tuvo una posición de crítica contra las instituciones financieras internacionales. Sin embargo, 
nunca dejó de pagar sus obligaciones o de asistir a los encuentros. De igual manera, China se presenta como un poder alternativo, diferente a Estados Unidos, pero no plantea siquiera la posibilidad de abandonar su puesto permanente en el Consejo de Seguridad. Lo mismo podría decirse de Rusia. India ha liderado un bloque que impide el avance de las negociaciones en el marco de la Organización Mundial del Comercio, pero no ha retrocedido en las políticas, de inicios de la década de los noventa, de apertura comercial, aunque esta sea tímida.

En el segundo caso, todos los países afirman su preferencia por valores diferentes a los que imperan en el sistema internacional actual y por relaciones de cooperación y de diálogo en contra de la guerra. No obstante, en todos los casos, la institución de la soberanía - principio esencial del sistema internacional occidental—, es prioritaria: Rusia (Ucrania), China (Taiwán, Hong Kong), Brasil (Amazonas), India (Pakistán) y Sudáfrica (Lesotho). De igual manera, a pesar de su retórica en favor de la paz y de la cooperación internacional, algunos de estos países tienen, en sus zonas de influencia, asuntos no resueltos que pueden desencadenar enfrentamientos bélicos en cualquier momento. Ejemplo de esto son los problemas navales de China, el expansionismo ruso y las (re)nacientes tensiones entre India y Pakistán.

Se decidió de manera intencional hablar de dualidad y no de contradicción. Los anteriores hechos no deben entenderse como una calificación de la actuación internacional de estos países. No es un juicio de valor. No se puede calificar de hipócrita o de adecuada una u otra actuación. Más bien, es una expresión de las características objetivas de estos países lo que lleva a que adelanten, de manera simultánea, acciones que podrían catalogarse como contradictorias. Tampoco se trata de explicar por qué surge, por ejemplo, la importancia de la soberanía para estos países. Eso podría ser parte de otro estudio: si es por imposición de ideas y valores, si es por el proceso de consolidación del Estado o si es por el pasado colonial. En este documento se trata de partir de estos asuntos que permiten caracterizar a los países BRICS y preguntarse cómo pueden esas realidades incidir en su ascenso como potencias. 
Por su parte, el reconocimiento de la existencia de estas dualidades hace que el estudio acá propuesto pueda limitarse a los discursos oficiales o a las fuentes. De hecho, el quedarse en esto puede ser una de las causas principales de confusión de los analistas sobre las implicaciones del ascenso de estos países. Como se señaló, una cosa es lo que se afirma en esos discursos y otra lo que se ve en la práctica. En este sentido, tendría que hacerse el estudio, no a través de las preferencias anunciadas por los actores, sino de las reveladas ${ }^{8}$ (Jehle \& Reny, 2001, pp. 86-92).

Los países BRICS pueden considerarse un actor contrahegemónico debido a su interés por presentarse como contrapeso al papel de Estados Unidos y como alternativa al predominio de los valores occidentales. Así, ante la propuesta de un Área de Libre Comercio de las Américas (ALCA), liderada por Estados Unidos, Brasil contrapone procesos de integración suramericanos (Unasur) o detiene el avance del ALCA, como sucedió en 2005. Sudáfrica lidera una lucha en contra de las farmacéuticas internacionales con el fin de producir genéricos que puedan ser utilizados en su lucha contra el VIH/SIDA. India, como se mencionó, es uno de los líderes que presiona a los países desarrollados para que se comprometan a eliminar los subsidios agrícolas en el marco de la OMC. Rusia y China son abiertamente contrahegemónicos en la mayoría de sus actuaciones internacionales.

Por su parte, estos países no cuentan con niveles de desarrollo semejantes a los de las potencias occidentales, pero están en proceso. En la tabla 1 se pueden observar algunos datos comparativos.

\footnotetext{
8 En microeconomía se parte de la existencia del supuesto de que las preferencias de los agentes cumplen unas propiedades que las hacen susceptibles de aplicarles análisis matemático. Dentro de ellas se encuentra que las preferencias son completas, transitivas y estrictamente monotónicas. No obstante, otra forma de estudiar el comportamiento de los actores no es asumiendo esas propiedades sino observando el patrón de consumo efectivo. Esto no es más que analizar el comportamiento, no por lo que se espera que hagan los actores, sino por lo que efectivamente hacen.
} 
Tabla 1. Indicadores seleccionados

\begin{tabular}{|c|c|c|c|c|c|c|c|c|c|c|c|c|}
\hline \multirow[b]{2}{*}{ Indicador } & \multicolumn{12}{|c|}{ Posición del país en el mundo (ránquines) o cifra (2014) } \\
\hline & : & $\cdot \frac{\pi}{6}$ & 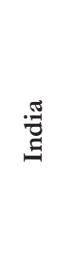 & 苞 & 葛 & 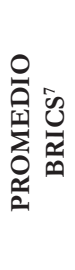 & 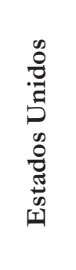 & $\frac{\pi}{\stackrel{\pi}{*}}$ & 武 & 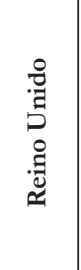 & 葛 & 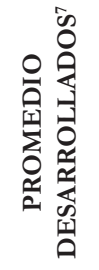 \\
\hline $\begin{array}{l}\text { Índice de desarrollo } \\
\text { humano }^{1}\end{array}$ & 75 & 50 & 130 & 90 & 116 & 92,2 & 8 & 6 & 22 & 14 & 20 & 14 \\
\hline $\begin{array}{l}\text { Índice de } \\
\text { competitividad }^{1}\end{array}$ & 57 & 53 & 71 & 28 & 56 & 53 & 3 & 5 & 23 & 9 & 6 & 9,2 \\
\hline $\begin{array}{l}\text { PIB per capita (USD } \\
\text { corrientes) }\end{array}$ & 11284 & 12736 & 1582 & 7590 & 6483 & 7935 & 54630 & 47822 & 42733 & 46332 & 36194 & 45542,2 \\
\hline $\begin{array}{l}\text { Agricultura, valor } \\
\text { añadido }(\% \mathrm{PIB})^{2}\end{array}$ & 5,6 & 4,2 & 17,8 & 9,2 & 2,5 & 7,86 & 1,4 & 0,7 & 1,7 & 0,7 & 1,2 & 1,14 \\
\hline $\begin{array}{l}\text { Industria, valor añadido } \\
(\% \mathrm{PIB})^{2}\end{array}$ & 23,4 & 35,8 & 30,1 & 42,7 & 29,5 & 32,3 & 20,5 & 30,8 & 19,4 & 21 & 26,2 & 23,58 \\
\hline $\begin{array}{l}\text { Servicios, valor añadido } \\
(\% \mathrm{PIB})^{2}\end{array}$ & 71 & 60 & 52,1 & 48,1 & 68 & 59,84 & 78,1 & 69 & 78,9 & 78,4 & 72,6 & 75,4 \\
\hline $\begin{array}{l}\text { Expectativa de vida al } \\
\text { nacer (años) }\end{array}$ & 74 & 71 & 68 & 75 & 57 & 69 & 79 & 81 & 82 & 81 & 83 & 81,2 \\
\hline $\begin{array}{l}\text { Agua potable }(\% \\
\text { población rural) }\end{array}$ & 87 & 91 & 93 & 93 & 81 & 89 & 98 & 100 & 100 & 100 & 100 & 99,6 \\
\hline $\begin{array}{l}\text { Acciones transadas }(\% \\
\text { del PIB) }\end{array}$ & 27,6 & 8,6 & 35,7 & 115,5 & 92,7 & 56,02 & 236,9 & 34,8 & 41,5 & 41,6 & 105,3 & 92,02 \\
\hline $\begin{array}{l}\text { Servidores de Internet } \\
\text { seguros (por millón de } \\
\text { personas) }\end{array}$ & 69 & 84 & 6 & 7 & 116 & 56,4 & 1548 & 1420 & 683 & 1291 & 912 & 1170,8 \\
\hline $\begin{array}{l}\text { Ingresos del gobierno por } \\
\text { impuestos }(\% \text { del PIB })^{3,4}\end{array}$ & 14,4 & 15,1 & 10,8 & 10,4 & 25,5 & 15,24 & 10,2 & 11,5 & 21,4 & 25,1 & 10,1 & 15,66 \\
\hline $\begin{array}{l}\text { Gasto en I\&D } \\
(\% \text { del PIB })^{5}\end{array}$ & 1,15 & 1,13 & 0,82 & 2,01 & 0,73 & 1,168 & 2,81 & 2,85 & 2,23 & 1,63 & 3,47 & 2,598 \\
\hline $\begin{array}{l}\text { Exportaciones de bienes } \\
\text { y servicios }(\% \text { del PIB })^{6}\end{array}$ & 11,5 & 30 & 23,2 & 22,6 & 31,3 & 23,72 & 13,5 & 45,7 & 28,7 & 28,4 & 16,2 & 26,5 \\
\hline
\end{tabular}

Tabla elaborada por el autor con información del sitio web del Programa de las Naciones Unidas para el Desarrollo (PNUD), del Foro Económico Global y del Banco Mundial.

${ }^{1}$ En ambos casos, se trata de los puestos que ocupa cada país en estos ránquines. En el IDH, la clasificación se da entre 188 países y en el de competitividad entre 144 .

${ }^{2}$ Para estos tres indicadores, los datos de Estados Unidos y Japón son de 2013.

${ }^{3}$ Este indicador tiene datos para 2012 en la mayoría de países.

${ }^{4}$ Los datos de China son de 2011.

${ }^{5}$ Los gastos en Investigación \& Desarrollo son de 2011 para India; de 2012 para Brasil, Sudáfrica y Estados Unidos; de 2013 para el resto de países.

${ }^{6}$ Los de Estados Unidos y Japón son datos de 2013.

${ }^{7}$ Los promedios son solo para indicar el tipo de diferencias. No tienen valor científico. 
En esta tabla son evidentes las diferencias entre los países BRICS y algunos de los países reconocidos como desarrollados. Antes de observar la tabla, los datos demuestran dos hechos que se deben tener en cuenta. Primero, la dificultad de medir el desarrollo. Si se comparan casos puntuales, se puede observar que, de acuerdo a algunos datos, hay países BRICs que tienen resultados de países desarrollados o viceversa. Esto lleva al segundo punto: si este fuera una escrito sobre desarrollo, sería necesaria una base de datos más completa con el fin de establecer rasgos característicos, en particular de los países desarrollados. No obstante, con los casos escogidos, se pueden mostrar algunas diferencias relevantes.

La brecha entre países desarrollados y los BRICS aún se mantiene. Por ejemplo, mientras que los primeros se ubican, en promedio, en el puesto 14 entre 188 economías en el índice de desarrollo humano (IDH), los segundos se ubican en el puesto 92 en promedio. La diferencia también es importante en competitvidad. El PIB per cápita de los desarrollados es casi cinco veces el de los BRICS.

Lo anterior se refleja en la composición del PIB de los países. En promedio, los países desarrollados tienen una economía basada en servicios $(75,4)$, mientras que los BRICS tienen aún una importante actividad en los sectores agrícola e industrial. Un elemento adicional lo proporciona el dato de acciones transadas. El guarismo resulta de la multiplicación del número de acciones que se transan en cada país por su precio de mercado. Si bien existen casos como el de China que tiene un comportamiento de país desarrollado en este ámbito, o el de Francia, Alemania y Reino Unido, que tienen resultados de país no desarrollado, en promedio el tamaño del mercado de capitales en los países desarrollados es mucho mayor que en el de los BRICS. Como se verá más adelante, estos datos pueden servir de insumo para establecer posibles comportamientos de estos actores en el ámbito internacional.

El nivel de desarrollo también se refleja en los indicadores sociales. Los países desarrollados ofrecen más de doce años adicionales de expectativa de vida al nacer en comparación con la de los BRICS. De igual manera, existe en los primeros casi una cobertura total de agua 
potable en las zonas rurales. Por su parte, los ciudadanos de los países desarrollados tienen más de veinte veces más servidores seguros de Internet que los de los países BRICS 9 . En los países desarrollados se invierte (tanto en el sector privado como en el público) casi el doble, en promedio, y en términos porcentuales frente al PIB, que en los países BRICS.

Dos últimas observaciones. Es importante notar cómo casi no son diferentes los resultados ni en impuestos como porcentaje del PIB ni en exportaciones como porcentaje del PIB. No obstante, en ambos casos, existen unos resultados superiores en los países desarrollados, en promedio, jalonados en ambos casos, por los países europeos.

Lo anterior es importante, porque, antes de pasar a la siguiente parte, se aborda, con criterios objetivos, el carácter antihegemónico de los países BRICS. Existe un indicador que sirve para mostrar tanto que estos últimos son países no desarrollados como que son países antihegemónicos. Este es el Índice de Libertad Económica. De los dos índices existentes que miden la libertad económica de los países (qué tanto interviene el Estado en las decisiones económicas individuales), se utilizará el desarrollado por la fundación Heritage en Estados Unidos ${ }^{10}$.

Tabla 2. Índice de Libertad Económica Heritage Foundation

\begin{tabular}{|c|c|c|c|c|c|c|c|c|c|c|c|c|}
\hline ص & 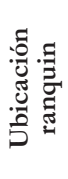 & 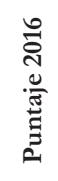 & 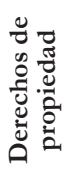 & 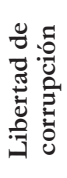 & 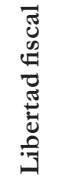 & $\begin{array}{l}\stackrel{0}{0} \\
: 0 \\
0 \\
0 \\
0 \\
0 \\
0 \\
0 \\
0\end{array}$ & 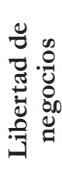 & 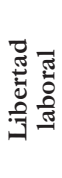 & 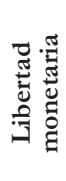 & 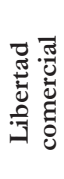 & 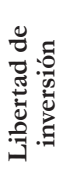 & 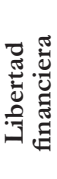 \\
\hline Brasil & 122 & 56,5 & 45,0 & 43,0 & 69,7 & 55,2 & 61,4 & 52,5 & 64,2 & 69,4 & 55 & 50 \\
\hline China & 144 & 52,0 & 20,0 & 36,0 & 69,7 & 74,3 & 54,2 & 62,0 & 70,6 & 72,8 & 30 & 30 \\
\hline Francia & 75 & 62,3 & 80,0 & 69,0 & 47,7 & 2,5 & 78,4 & 43,5 & 79,1 & 83 & 70 & 70 \\
\hline Alemania & 17 & 74,4 & 90,0 & 79,0 & 61,5 & 41,3 & 90 & 50,6 & 83,3 & 88 & 90 & 70 \\
\hline India & 123 & 56,2 & 55,0 & 38,0 & 77,1 & 78,1 & 47,6 & 47,8 & 72,8 & 71 & 35 & 40 \\
\hline
\end{tabular}

Continúa

9 Esto puede indicar el potencial de avance del comercio electrónico y otras transacciones virtuales.

10 El otro índice, más utilizado, es el del instituto Fraser de Canadá. 


\begin{tabular}{|c|c|c|c|c|c|c|c|c|c|c|c|c|}
\hline$\stackrel{0}{\pi}$ & 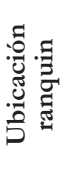 & 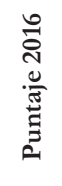 & 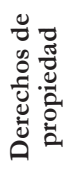 & 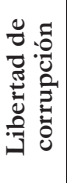 & 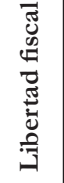 & 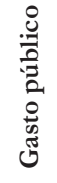 & 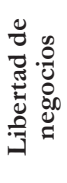 & 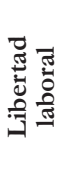 & 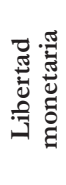 & 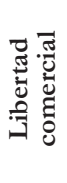 & 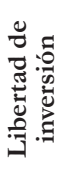 & 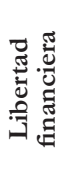 \\
\hline Japón & 22 & 73,1 & 80,0 & 76,0 & 68,5 & 46,2 & 82,5 & 83,9 & 81,2 & 82,6 & 70 & 60 \\
\hline Rusia & 153 & 50,6 & 20,0 & 27,0 & 82,2 & 56,2 & 72,2 & 57,6 & 62,9 & 72,4 & 25 & 30 \\
\hline Sudáfrica & 80 & 61,9 & 50,0 & 44,0 & 70,1 & 69,9 & 69,7 & 58,7 & 74,6 & 77 & 45 & 60 \\
\hline Reino Unido & 10 & 76,4 & 90,0 & 78,0 & 64,9 & 39,0 & 86 & 71,8 & 76,4 & 88 & 90 & 80 \\
\hline $\begin{array}{l}\text { Estados } \\
\text { Unidos }\end{array}$ & 11 & 75,4 & 80,0 & 74,0 & 65,6 & 54,7 & 84,7 & 91,4 & 77,0 & 87 & 70 & 70 \\
\hline
\end{tabular}

\begin{tabular}{|l|c|c|c|c|c|c|c|c|c|c|c|c|}
\hline $\begin{array}{l}\text { Promedio } \\
\text { BRICS }\end{array}$ & 124 & 55 & 38 & 38 & 74 & 67 & 61 & 56 & 69 & 73 & 38 & 42 \\
\hline $\begin{array}{l}\text { Promedio } \\
\text { desarrollados }\end{array}$ & 27 & 72 & 84 & 75 & 62 & 37 & 84 & 68 & 79 & 86 & 78 & 70 \\
\hline $\begin{array}{l}\text { Diferencia } \\
\text { desarrollados } \\
\text { menos BRICS }\end{array}$ & -97 & 17 & 46 & 38 & -12 & -30 & 23 & 13 & 10 & 13 & 40 & 28 \\
\hline
\end{tabular}

Tabla elaborada por el autor con los datos del Index of Economic Freedom 2016 de la Fundación Heritage.

En la tabla anterior (tabla 2) se muestran los resultados para los países seleccionados en el Índice de Libertad Económica. Se mantuvo la obtención de promedios con fines ilustrativos. Es evidente que los BRICS, en promedio, tienen estrategias de crecimiento basadas en modelos de economías no liberalizadas. Este hecho es una demostración del carácter antihegemónico de estos países porque resalta, en la práctica y en términos de política pública doméstica, su oposición a los valores que defienden los países occidentales, en general, y Estados Unidos, en particular. Nótese que, como sucedió en la observación de datos, en esta muestra se repite el hecho de que los países BRICS resultan más abiertos que sus pares desarrollados cuando se trata de la libertad fiscal y del gasto público.

Es importante resaltar este hecho porque no se puede caracterizar el ámbito internacional actual como uno únicamente liberal. Si se rastrea su configuración y evolución desde finales de la Segunda Guerra Mundial, el entorno internacional que existe se basa en valores 
liberales, como han señalado diversos autores (Ikenberry, 2011; Kissinger, 2014). No obstante, estos mismos autores, así como otros, han mostrado cómo se ha sostenido un consenso sobre la necesidad de la intervención de los Estados en el ámbito doméstico para alcanzar objetivos puntuales de bienestar o de regulación de las empresas, entre otros. En el mismo sentido, el consenso se extiende al ámbito internacional mediante la visión sobre la necesidad de establecer organizaciones internacionales con funciones de regulación de las relaciones entre Estados, así como de facilitar y mediar la identificación, formulación y puesta en marcha de asuntos que son considerados objeto de lo que se ha denominado gobernanza global (Avant, Finnemore \& Sell, 2010). De esta manera, una buena aproximación que explica la complejidad del ámbito internacional actual es la denominación, propuesta por Ruggie (1982), de liberalismo incrustado (embedded liberalism).

A continuación se tratarán, teniendo como insumo la caracterización propuesta de los países BRICS, algunos elementos que pueden tomarse en cuenta para conjeturar sobre el impacto de un eventual ascenso de estos países como potencias globales.

\section{Implicaciones: ¿Un mejor sistema internacional?}

El que tantos autores, de diversas regiones y especialidades, hayan asumido una posición optimista sobre lo que percibían como un inminente ascenso de los países BRICS (O BRIC, hace algunos años) implica que consideraban, de una manera u otra, que un mundo liderado por estos países sería uno mejor (Brawley, 2007; Flemes, 2013; Mielniczuk, 2013; Vlad, et al., 2011; Yuequin, 2010).

Ahora bien, ¿cuáles pueden ser los criterios para caracterizar un sistema internacional como mejor? A partir de la evolución de las teorías de relaciones internacionales, de la observación de las presunciones que hacen los autores que han abordado el tema de los BRICS y, de manera general, de los temas recurrentes en los estudios y análisis internacionales, se pueden establecer varios criterios que pueden no agotar el total de alternativas posibles. 
Acá, se considerarán las siguientes: un sistema internacional sería mejor si fuera más pacífico, más justo, más incluyente y más estable. Estas características parecen surgir de la revisión superficial ${ }^{11}$ de las fuentes mencionadas. En cada uno de los apartados, además, se proporcionarán las acepciones posibles de cada uno de los términos y la forma como se considera se entienden, en general, en la literatura. A continuación se aborda cada uno de ellos.

\section{¿Un mundo más pacífico?}

Un sistema internacional más pacífico puede incluir tres elementos. Primero, la ausencia de enfrentamientos interestatales. Segundo, la ausencia de intervención de los países potencia en otros países con menor poder. Tercero, la resolución de conflictos intraestatales.

Este último, a pesar de ser un tema de la agenda de seguridad internacional, no puede ser la acepción generalmente utilizada por los autores. No importa cuál sea el país que detente más poder, los conflictos seguirán teniendo causas complejas que incluyen lo doméstico. De igual manera, serán complicadas sus dinámicas y posibles soluciones. Considerar que la resolución de estos conflictos será mayor si los países BRICS son los nuevos poderes mundiales, es desconocer todo lo anterior.

Las primeras dos acepciones pueden ser las que más consideran los autores. La primera, sin embargo, resulta algo inexacta frente a la situación actual. Cualquiera que sea la razón, el número de conflictos entre Estados en el actual sistema internacional, el de liberalismo incrustado, se ha reducido casi a cero desde la Segunda Guerra Mundial. Por esto, es posible que la visión de los autores tenga que ver principalmente con la segunda acepción: la de la intervención.

Es innegable que Estados Unidos, desde su ascenso como potencia y luego como superpotencia, ha adelantado una política exterior que

\footnotetext{
11 Esto no implica descuidada. Se denomina superficial porque no se adelantó un estudio a través de análisis del discurso ni ninguna metodología semejante para sacar estas conclusiones.
} 
utiliza de manera reiterada intervenciones militares en diferentes países del mundo. Tal vez los analistas consideran que esto cambiaría ante un eventual ascenso de los países BRICS por dos razones. Primero, porque hasta el momento estos países han utilizado medios diplomáticos y de cooperación en su relación con el resto del mundo. Segundo, porque al ser cinco los países potencia, su capacidad de intervención unilateral se vería reducida o, en todo caso, controlada por los demás.

La primera razón es débil, por decir lo menos. El que estos países hayan privilegiado hasta ahora una política exterior basada en la cooperación y la diplomacia no indica que siempre lo harán. Esto se puede deber, por ejemplo, a que aún no cuentan con la suficiente fuerza militar para alcanzar sus objetivos internacionales. También a que todavía no son los promotores de las normas internacionales $y$, por lo tanto, no deben jugar el papel de ejecutores (enforcers).

La segunda razón también se puede poner en duda. Los hallazgos de diferentes estudios en los que se aplica la teoría de juegos para predecir guerras en el ámbito internacional indican que se requieren muchas más condiciones para concluir que, ante un eventual ascenso de los países BRICS, se enfrentaría un sistema internacional más pacífico en cualquiera de las dos primeras acepciones.

Esta teoría se aplica en el caso de un eventual ascenso de los BRICS porque sus decisiones, en materia de si atacar o no, serían estratégicas. Esto es, serían interdependientes de las decisiones que tomasen los demás actores. Así las cosas, no estaría garantizada la decisión, por parte de todos los actores, de siempre responder como palomas (doves).

En la teoría de juegos, quienes intervienen escogen su mejor opción anticipando el comportamiento de los demás. Esto es importante para este caso porque, a diferencia de un sistema internacional liderado por una sola superpotencia, el ascenso de múltiples poderes, cada uno con sus intereses y objetivos, incrementaría las lógicas de interacción entre pocos actores. En la literatura especializada se ha reconocido que en la actuación estratégica los actores se preocupan mucho por los asuntos así que tratan de no actuar por reacción sin pensar. Es 
decir, los actores conocen los asuntos y a los demás actores (Sprinz \& Wolinsky-Nahmias, 2007, p. 305; Szilagyi, 2003).

Por otro lado, incluso si la existencia de cinco potencias líderes consistiese en su actuación constante a través de lógicas de cooperación, esto no deja de lado que, según los aportes hechos por Axelrod (2006), esta estrategia puede ser penetrada por una de no cooperación. Para evitar este fenómeno, en consecuencia, es necesario que las potencias existentes demuestren su compromiso, no solo con la cooperación, sino también con la penalización de la no cooperación (Sprinz \& Wolinsky-Nahmias, 2007, p. 350; Oye, 1986).

Fuera de los aportes hechos por la teoría de juegos, un eventual liderazgo de los países BRICs podría asemejarse a un sistema internacional de carácter oligopólico. En la literatura de relaciones internacionales se encuentran estudios que consideran que un sistema internacional unipolar es el adecuado (teoría de la estabilidad hegemónica) o, incluso, uno bipolar (Waltz, 1979). A pesar de las críticas hechas a ambas posturas, no existe ninguna aproximación que considere superior un sistema internacional de tipo oligopólico.

Dentro de las lógicas de actuación de un sistema internacional con estas características, no se debe olvidar ni la actuación estratégica de las potencias líderes, ni la necesidad que encontraría cada una de mantener su cuota del mercado y de reducir la incertidumbre (Sprinz \& Wolinsky-Nahmias, 2007, pp. 299-301). Por consiguiente, un sistema oligopólico puede fomentar las alianzas entre sus líderes pero estas no son necesariamente estables (Sprinz \& Wolinsky-Nahmias, 2007, p. 300).

Un último elemento es el de la información. La cooperación o no, la posibilidad de alianzas o no y, en últimas, la generación de un sistema internacional pacífico depende, en el caso de decisiones estratégicas, de la información disponible para los actores. La literatura demuestra la importancia para cada uno de contar con información veraz y transparente con el fin de evitar accidentes, errores y percepciones equivocadas (Sprinz \& Wolinsky-Nahmias, 2007, p. 251; p. 355). 
Además, la reputación que se ganen los líderes depende de la información que reciban los demás actores. En este caso, la existencia de amenazas creíbles, por ejemplo, a través de declaraciones públicas que anticipen el castigo ante cualquier no cooperación (Sprinz \& Wolinsky-Nahmias, 2007, p. 254).

No se debe olvidar que las características internas de los actores determinan la posibilidad de la existencia de juegos cooperativos (en los que se pueden hacer acuerdos de distribución de beneficios) o no cooperativos con información completa e incompleta (Sprinz \& Wolinsky-Nahmias, 2007, pp. 319-329).

Las características implican el tipo de régimen existente. No obstante, no todo se reduce a la existencia de un régimen democrático. Algunos autores cuestionan la doctrina de la paz democrática. Si se considera que esta responde a razones teóricas, más que circunstanciales y empíricas, por lo menos cuatro visiones que explican su lógica interna plantean otros elementos importantes para analizar un eventual liderazgo de países que no necesariamente comparten los componentes y elementos del régimen democrático, en general, y mucho menos del liberal, en particular.

Primero, está la visión normativa según la cual la observación de la paz democrática resulta de la existencia de normas específicas de las democracias tales como la autodeterminación de los pueblos y el imperio de la ley (Sprinz \& Wolinsky-Nahmias, 2007, p. 357). Segundo, algunos autores adelantan una explicación estructural. Esto es, los líderes democráticos están limitados por la presión de la opinión pública (Sprinz \& Wolinsky-Nahmias, 2007, p. 357). Una tercera explicación es la informacional: las democracias son mejores al señalar (signaling) su decisión de cooperar o no cooperar porque son más transparentes (Sprinz \& Wolinsky-Nahmias, 2007, p. 357). La última explicación consiste en asumir que las democracias tienen costos más altos para adelantar guerras (Sprinz \& Wolinsky-Nahmias, 2007, p. 358.) 
Como es evidente, todas las explicaciones anteriores pueden ser debatidas. De hecho, la doctrina según la cual las democracias no hacen la guerra entre sí podría no existir debido a que los autores que la han estudiado podrían haber considerado ex post casos de democracias que no lo fueran o viceversa y así caer en errores de sesgo de confirmación. No obstante, lo que acá se quiere resaltar es cómo existen muchos elementos que no necesariamente implican que el mero ascenso de los países BRICS automáticamente cree un sistema internacional más pacífico.

En últimas, lo anterior depende de la naturaleza de lo actores. Los actores domésticos demuestran sus preferencias (Sprinz \& WolinskyNahmias, 2007, p. 258; Putnam, 1988). Esto ha llevado, en la literatura, al reconocimiento de los juegos de dos niveles (two level games) en los que son relevantes los actores domésticos porque así se puede recabar información veraz, transparente, reducir la incertidumbre y, además, reconocer cuándo una amenaza es creíble. No obstante, estos juegos dependen de la existencia de sistemas democráticos con procesos parlamentarios, del conocimiento de las preferencias de los tomadores de decisiones y de aquellos que definen el proceso de negociación (Sprinz \& Wolinsky-Nahmias, 2007, pp. 322-323).

Además de los anteriores, la literatura demuestra lo importante que es la dinámica en el comportamiento de los actores en términos de emulación de buenas prácticas para asumir comportamientos futuros (Sprinz \& Wolinsky-Nahmias, 2007, p. 259). En el caso de los países BRICS, habría que ver cuáles son las fuentes de aprendizaje que tienen sus gobiernos y la forma cómo interpretan la retroalimentación de las decisiones que toman.

Para finalizar este apartado, a partir de los elementos mencionados, es claro que no es suficiente un eventual liderazgo de más países o de países cuya naturaleza sea de no desarrollados, para concluir automáticamente que se generará un sistema internacional más pacífico. Para afirmar esto, tendría que demostrarse que, por su naturaleza, estos sí tendrán relaciones de cooperación entre ellos y con el resto del mundo, a diferencia de las potencias actuales. Conflicto o no conflicto depende 
de la situación de crisis y de negociación que surge de la existencia de conflictos de interés (Fearon, 1995) y de información incompleta (Powell, 1990; Morrow, 1989). No importan tanto los conflictos de intereses o la anarquía. No es suficiente (Sprinz \& Wolinsky-Nahmias, 2007, p. 356). Lo es más la negociación (bargaining), la incertidumbre, las creencias y el signaling.

Una última observación, empírica, en este apartado consiste en que ninguno de los países BRICs ha demostrado una aproximación diferente a la cuestión territorial. De hecho, se podría señalar que en todos ellos persiste una visión tradicional del territorio y de la soberanía, lo que podría entenderse como enmarcado en las lógicas de autoayuda que abordaron los realistas y neorrealistas de las teorías de relaciones internacionales y que también ha sido incluida en la imagen de sistema internacional hobbesiano aportado por Wendt (1999). Los países BRICs han explicado sus procesos de fortalecimiento militar a partir de justificaciones que pueden enmarcarse en las lógicas del dilema de seguridad (Herz, 1950; Jervis, 1978).

\section{¿Un sistema internacional más justo?}

En la filosofía y la teoría políticas existen, al menos, dos tradiciones sobre qué es la justicia. Estas han trascendido al análisis del ámbito internacional. Por un lado, está la tradición del liberalismo clásico según la cual la justicia significa igualdad ante la ley (Audard, 2009). Otra visión, aportada principalmente por Rawls (1999), consiste en que la justicia es entendida como una pretendida disminución de las desigualdades materiales (Rawls la llama justicia como equidad).

En política internacional hay escepticismo sobre las posibilidades de la primera tradición como resultado de la inexistencia de un gobierno mundial. Esto ha llevado, según se considera, a que las normas y reglas no tengan mecanismos de sanción ante las desviaciones, como es el caso de las decisiones de las cortes internacionales. De igual manera, se ha considerado que la tensión entre derecho y poder en el ámbito global hace que este último sea meramente un instrumento para los más poderosos o la única estrategia de protección de los menos poderosos. 
Fuera de algunos autores, no se ha observado cómo las desviaciones del derecho internacional no son la norma, así como estas son adelantadas por algunos actores cuya reputación se ha construido de esta manera. Autores como Beth Simmons o Robert Axelrod han propuesto algunos pocos elementos de los fenómenos de autocumplimiento que son resultado de sentimientos de vergüenza o de culpa que también se presentan en el ámbito internacional.

En consecuencia, la segunda visión de la justicia ha sido la preferida por muchos de los actores en el sistema internacional. Dentro de ellos se encuentran los países BRICs. Más que la ley internacional, las políticas exteriores de estas potencias en ascenso se ha concentrado en la promoción de la justicia como redistribución.

Desde esta aproximación, las normas no pueden ser minimalistas para, por ejemplo, evitar el uso de la guerra, sino maximalistas. Las normas no se aplican de manera predecible en todos los momentos y a todos los actores de igual manera, sino que dependen de otros criterios, tanto las reglas como su aplicación. Cuáles son esos criterios, quién los determina y a quiénes se les aplica se debe decidir por intermedio de entes centrales. Esto implicaría que sean los países BRICS los encargados de todo este proceso.

¿La redistribución se hace bajo criterios de necesidad o de mérito? ¿Quiénes pagan? ¿Quiénes reciben? ¿Qué monto? ¿Cómo se determina la necesidad? ¿Cómo el mérito? Todas estas preguntas requieren de una respuesta por parte de quienes lideran o liderarían el sistema internacional.

Para analizar las implicaciones de este hecho, también existen contribuciones de autores a la economía política internacional. Aplicando los supuestos básicos de la microeconomía, se considera que estos pretenden maximizar su utilidad. Esto es, ser más eficientes en la consecución de sus objetivos (Sprinz \& Wolinsky-Nahmias, 2007, p. 270). Dentro de estos objetivos, ¿son las ganancias de los demás parte de las consideraciones o no? Esta pregunta no tiene una respuesta fácil, pero no es claro que en el caso de los BRICs esta sea positiva. Así las cosas, se trata de maximizar su utilidad pensada en sus 
términos, lo cual implica dificultades en la forma cómo son abordadas las preguntas que determinarán los criterios de justicia en el ámbito internacional en su segunda acepción.

Además, para entender la derivación de los intereses, se parte de la importancia de las preferencias de los actores. Según lo anterior, las de los países diferentes a los BRICS no serían tenidas en cuentas. Por su parte, las de estos países incluyen su situación de desarrollado que, a su vez, en los casos de los cinco países, se considera un objetivo a adelantar, liderar y coordinar con el Estado.

De igual manera, no se puede olvidar el papel del ámbito doméstico y de los intereses de los factores de la producción o de los sectores (Sprinz \& Wolinsky-Nahmias, 2007, p. 277). En consecuencia, la determinación de los criterios de justicia redistributiva estaría limitada por los intereses y preferencias de los países BRICS. A su vez, estas dependen de las necesidades de desarrollo y de los sectores productivos considerados estratégicos o en desventaja en términos de crecimiento. No sería entonces un sistema internacional cuyo criterio de justicia redistributiva sería, por ejemplo, la apertura comercial, sino al contrario el proteccionismo selectivo, iniciado, liderado, por las potencias centrales.

Además de la derivación de preferencias, la determinación sobre si un sistema internacional es más justo bajo la acepción acá utilizada incluye el componente de la provisión de bienes públicos internacionales. Tradicionalmente, las potencias han sido los oferentes de este tipo de bienes dentro de los que se incluye la seguridad, la liquidez internacional y la supervisión en el cumplimiento de las normas internacionales. No se pretende afirmar que esta provisión se haga con fines altruistas o desinteresados. La razón puntual no forma parte del análisis. El punto es que, históricamente, las potencias dominantes se han encargado de estos asuntos.

Tampoco se trata de afirmar que lo hagan siempre ni frente a todos los actores. Las potencias han sido selectivas acerca de en qué tipos de seguridad garantizar, frente a qué actores y en qué momentos. Lo 
mismo podría decirse del cumplimiento de las normas. No se hace cumplir todas las normas ni se sanciona a todos los infractores. A pesar de esto, las potencias lo hacen, aunque de manera selectiva.

Por consiguiente, en el caso de los países BRICS, la provisión no requeriría ser altruista ni completa (en términos temporales y de actores). Pero tampoco se puede asumir que sí lo sería. Más bien, habría que concentrarse en observar cómo se haría el proceso de provisión. ¿Habría una mejor provisión de estos bienes públicos globales?

Ante los problemas que configuran la denominada tragedia de los comunes, caracterizada por la utilización de un bien que es no excluyente pero sí rival, Ostrom (1990) demostró que si el grupo de participantes es pequeño, es más fácil darles solución. Sin embargo, dentro de las condiciones establecidas se encuentran la de la transparencia en la interacción y el constante contacto cara a cara (Sprinz \& Wolinsky-Nahmias, 2007, p. 326). Los países BRICs han creado organizaciones internacionales que facilitan los contactos constantes cara a cara. Además, al ser un oligopolio, las soluciones a las que se llegue pueden ser alcanzadas de manera más fácil. No obstante, como se mencionó en el apartado anterior, no es clara la transparencia en la interacción entre los países miembro.

Un elemento central que ilustra esto último y que también genera otros problemas es el de la provisión específica. Del lado de la seguridad, podría pensarse en una regionalización de las tareas. Pero la regionalización no es tan clara y puede ser contraproducente si se habla de la supervisión en el cumplimiento de las normas o de la liquidez internacional.

¿Cuál de los cinco países será el generador de normas? Si son los cinco, ¿Cómo será la jerarquía entre ellos? ¿Cómo evitar contradicciones? Pero el problema es más evidente en el ámbito de la liquidez internacional: ¿cuál será la moneda de uso internacional? Según los modelos de desarrollo mencionados en páginas anteriores, ¿estaría dispuesto alguno de los países BRICS a garantizar una liquidez suficiente para 
respaldar las transacciones internacionales, comerciales y financieras? Las respuestas a estas preguntas no son tan claras.

Además de las cuestiones mencionadas, que podrían ser solucionadas a través de estrategias procedimentales, la toma de decisiones conjunta y la provisión de bienes públicos globales podría promover, entre los países BRICs, la adopción por alguno(s) de ellos de estrategias de polizón (free-rider). La solución para ello no sería obvia, como tampoco lo sería que estos cinco países estuvieran dispuestos a asumir los costos de la provisión de esos bienes públicos sin esperar que los demás países del mundo también participaran.

Por último, la posibilidad de contar con un sistema internacional más justo en el sentido defendido por, entre otros, los países BRICS, requiere de la consolidación de organizaciones internacionales como las existentes en el sistema internacional actual. El punto está en que esas organizaciones, algunas de las cuales ya han sido creadas y están en funcionamiento, debido a que su naturaleza no sería diferente a la de las ya existentes, no solucionarían los problemas también ya existentes. Dentro de estos se encuentran los de riesgo moral y selección adversa (Sprinz \& Wolinsky-Nahmias, 2007, p. 305). Así las cosas, ¿podrían adelantar de mejor manera los procesos de redistribución de los recursos en el ámbito internacional?

\section{¿Un sistema internacional más incluyente?}

El sistema internacional vigente, basado en principios liberales, junto con una intervención del Estado en las economías domésticas y la preferencia por organizaciones internacionales para coordinar y estandarizar la intervención presente y futura es lo que John G. Ruggie capturó mediante el concepto de liberalismo incrustado (embedded liberalism). Desde este punto de vista, este sistema internacional es incluyente en su propia naturaleza. Se refiere tanto una inclusión negativa, en el sentido de que las normas son mínimas y, por lo tanto, dan la posibilidad al disenso y a prácticas diversas en el ámbito internacional, como a una positiva, en el sentido de que aquellos actores 
con menores capacidades económicas son objeto de ayuda directa internacional a través de las organizaciones y demás actores existentes.

No obstante, parece considerarse que el grado de inclusión de los actores no es suficiente. Desde este punto de vista, resulta evidente que no es clara la concepción que se tiene sobre un sistema internacional más incluyente. Sin embargo, esto puede indicar, más bien, que se considera que los países menos desarrollados se ven menos representados en los diversos escenarios internacionales y que, por lo tanto, sus intereses se ven afectados.

En consecuencia, para abordar esta cuestión, es necesario preguntarse si los países BRICS, impulsando unas normas diferentes a las actuales, pueden garantizar una mayor inclusión.

Para comenzar, a través de una aproximación histórica, North y Thomas (1973) demostraron que los costos relativos determinan las características de los sistemas productivos. Como ya se mencionó, el sistema de estas potencias emergentes, en las condiciones actuales, es proteccionista. Por lo tanto, y por definición, tal sistema no es incluyente. Una apertura sería muy costosa para su sistema de producción actual. Esto se puede extraer del hecho de que, como diferentes autores (Ver modelo Heckscher-Ohlin ${ }^{12}$; Sprinz \& Wolinsky-Nahmias, 2007, p. 298; Rogowski, 1989; Magee, Brock \& Young, 1989) mostraron, los dueños de los factores de la producción, según se vean afectados por políticas de apertura, presionarán para evitarla. Si, como parece ser el caso de China, Brasil o Rusia, el Estado es uno de los beneficiados directos de las políticas proteccionistas, es claro que las posibilidades de apertura de reducen.

Por otro lado, si la inclusión está medida en términos de la consecución de los intereses de los países menos desarrollados, habría que identificar de qué tipo de intereses se está hablando. Para simplificar el proceso, se podría asumir que el interés de estos países se encuentra

\footnotetext{
12 Se hace referencia al modelo de comercio internacional propuesto por estos actores, también llamado de factores específicos.
} 
en conseguir ventajas económicas en el escenario internacional. Es decir, en que prevalezca la lógica de justicia mencionada en el apartado anterior.

Bajo esta lógica, todo se reduce a considerar si la redistribución sería más incluyente que incluso bajo la alternativa existente en la actualidad. Lo primero que debe tenerse en cuenta es que cualquier política de redistribución sería de carácter involuntario debido a que, entre otras cosas, no hay disposición sobre quién(es) debe(n) hacer el esfuerzo (Sprinz \& Wolinsky-Nahmias, 2007, pp. 308-309). Los cinco países BRICS, no hay que olvidarlo, han manifestado que deben ser objeto de tratamiento diferenciado en el ámbito internacional porque aún no son países desarrollados. Es decir, estos países se consideran a sí mismos objeto de las políticas de redistribución.

En consecuencia, cualquier redistribución sería no voluntaria, lo que se vuelve más complejo cuando se tiene en cuenta que no es fácil establecer el parámetro de comparación de utilidades entre los actores (Sprinz \& Wolinsky-Nahmias, 2007, p. 309). Como ya se había señalado, es imposible establecer necesidad o mérito. Pero además, no es fácil establecer qué actores deberían establecer lo que es eficiente en términos de redistribución. ¿Cuánto es necesario? ¿Por cuánto tiempo? ¿Para quiénes?

Una forma de solucionar lo anterior sería la inclusión de los elementos que aportó Nozick (1977) sobre el principio de rectificación. Esto es, la rectificación de una redistribución pasada involuntaria. Acá se podría incluir la pretensión de algunos países no desarrollados, incluidos algunos de los BRICS, sobre una indemnización por el pasado colonial y sus excesos. No obstante, para adelantar tal política debería responderse hasta cuándo en el pasado se establecerán esas redistribuciones involuntarias y, de nuevo, quién debe decidirlo. Frente a esto, se abriría lugar a un serio problema de exclusión que se uniría al anteriormente identificado en este apartado, ¿no generaría problemas de legitimidad frente a la decisión que se tome el hecho de que sea liderada por aquellos que precisamente se consideran afectados? De igual manera, esta visión de la rectificación sobre el pasado solo 
podría legitimarse si se logra establecer por qué y en qué manera los derechos de propiedad individuales deben proyectarse en el plano social. ¿Cuál sería su fuente?

Además de estos problemas, un sistema internacional más incluyente tendría que pasar por reformar las prácticas vigentes que sirven como forma de toma de decisiones. En este sentido, los países BRICS no representan una alternativa a la visión estatocéntrica. Es más, podría incrementarse esta lógica si se tiene en cuenta la relación de algunos de estos países con sectores de la sociedad civil, incluidas las empresas.

Un último elemento para señalar es que pensar que los países BRICS generan un sistema internacional más incluyente es asumir que estos países no solo representan los intereses de los demás en una situación semejante de desarrollo o que siquiera pretenden serlo. Acá, las dudas son más que obvias.

\section{¿Un sistema internacional más estable?}

El último criterio a analizar, que también es resultado de los anteriores, es el de la estabilidad. Un sistema internacional estable no solo implica menos conflicto violento, más inclusión y justicia, normas y reglas más legítimas, así como mecanismos de sanción de los incumplimientos. La estabilidad también depende de la persistencia de las instituciones formales e informales internacionales en el tiempo y su grado de flexibilidad y de adaptación a los cambios que resultan de fenómenos generados por esas mismas instituciones o por fenómenos estocásticos.

Bueno de Mesquita (Sprinz \& Wolinsky-Nahmias, 2007, p. 293) ha planteado aportes que sirven para nutrir esta discusión. En este caso, los actores se comportan como consumidores. De esta manera, una mayor estabilidad es un bien que se demanda globalmente, en particular por los países potencia que, se puede esperar, tienen mayores intereses por mantener el statu quo. Al aplicar los conceptos básicos de la microeconomía, se podría esperar que el máximo de estabilidad dependerá de la solución para cada agente interesado en este bien; 
es decir, de la solución de su problema de maximización de utilidad con menores costos.

Esta solución estaría dada, para cada actor, por el punto en el cual la mayor curva de indiferencia posible sea igual a la línea de presupuesto. La línea de presupuesto se puede establecer de manera aparentemente sencilla si se tienen datos como el presupuesto nacional, la capacidad de intervención en los ingresos privados, entre otros.

No obstante, las curvas de indiferencia varían según la ordenación de preferencia, de carácter cualitativo, de cada actor. Estas son de muy difícil establecimiento ex ante. Sin embargo, uno de los elementos que incluye el autor es la aversión al riesgo. En este caso, este estaría determinado por la propensión a apoyar cambios o no al sistema internacional vigente.

En la actualidad, los países BRICS pueden tener un poco de aversión al riesgo debido a su papel de potencias revisionistas ${ }^{13}$. Aunque esta característica podría cambiar en caso de ser los líderes de un eventual nuevo sistema internacional. En ambos casos, la demanda por mayor estabilidad se vería afectada en igual medida. En caso de seguir siendo revisionistas, no habría mucha estabilidad en el sistema. En caso de convertirse en defensores del statu quo, se perdería flexibilidad y agilidad de respuesta, por lo tanto, se afectaría negativamente la estabilidad.

¿No hay opción? En la actualidad, Estados Unidos ha mezclado sus funciones de potencia revisionista y defensora del statu quo. Si los países BRICS adoptaran este mismo comportamiento no sería claro el cambio — en términos de mejora — ante un sistema liderado por las cinco potencias emergentes.

\footnotetext{
13 Véase el sentido que en este escrito se le da al término revisionista. Esto es importante porque, por lo menos en el discurso, potencias como China o Rusia se muestran - y son vistas - como jugadores defensores del statu quo. Se reconoce este hecho y se utiliza el término solo en el sentido de contrapeso al poder de la potencia actual: Estados Unidos.
} 
Es más, podría pensarse que el carácter de oligopolio ${ }^{14}$ de la agrupación podría afectar cualquier posibilidad de ejercer estrategias como la de Estados Unidos debido a que esta estructura de mercado es, por definición, altamente inestable y a que puede variar entre estrategias de guerra de precios o de colusión (Sprinz \& Wolinsky-Nahmias, 2007, p. 300).

\section{Conclusión: elementos para estudiar un sistema internacional multipolar}

Este artículo no pretende hacer futurología ni, mucho menos, entrar a un debate — no académico ni serio- sobre si es deseable que los BRICS se conviertan en potencias globales en remplazo de Estados Unidos. De lo que se trata es de recuperar, de la literatura de las relaciones internacionales, aquellos elementos útiles a la generación de análisis más rigurosos y menos concentrados en el deber ser o en la retórica de los actores.

En este sentido, su principal objetivo fue llamar la atención sobre la importancia de la teoría y de su relación con el método. La teoría como explicación de regularidades relacionales entre variables no solo debe aprovecharse para hacer análisis de política internacional, sino que debe fortalecerse y llenar sus vacíos. Tal vez la diversidad de explicaciones, de la que aquí se hace una aproximación, haya dado lugar a la visión de que no existen regularidades que deban ser explicadas en el ámbito de la política internacional. Pero esto no es cierto. Esa diversidad demuestra la complejidad de las explicaciones y, por lo tanto, de los fenómenos, pero no su inexistencia. En consecuencia, los análisis no se pueden hacer desvinculados de la teoría (de una teoría o de una síntesis de varias de ellas es otro debate) y mucho menos refugiados en percepciones sobre el "deber ser" de la política internacional.

\footnotetext{
14 Nótese que ahora se está haciendo el análisis de los BRICS como productores y no como consumidores.
} 
Del lado de los métodos, se hicieron observaciones sobre las condiciones de la pertinencia de algunos de ellos y sus limitaciones. No obstante, por la naturaleza prospectiva del tema abordado, se hizo énfasis en los modelos importados de la ciencia económica como un método legítimo de investigación y de verificación de resultados. Este método ha sido ignorado en gran parte de los estudios internacionales en América Latina, pero puede ser muy útil en análisis prospectivos. Una parte importante de las reflexiones que se hacen en esta disciplina son de este tipo. De ahí la necesidad de incrementar su uso, potencializar sus beneficios, reconocer sus límites y sofisticar su aplicación.

En cada uno de los rasgos identificados para referirse a un "mejor" sistema internacional, se encontraron aspectos que no se han tenido en cuenta y que hacen que no sea posible considerar automáticamente que un sistema internacional liderado por los BRICS sea más pacífico, incluyente, justo o estable, porque así estos lo quieran o lo manifiesten.

La conclusión no es determinista. Como no se puede afirmar con total seguridad que un sistema internacional de los BRICS sería mejor, tampoco se puede, por descarte, asumir que sería peor. Por ejemplo, es posible que las realidades de estos países bajo las que se le da contenido a los instrumentos analíticos acá consignados cambien en los próximos años. También podrían acentuarse. El aporte de esta reflexión es doble. De un lado, se resalta la riqueza teórica y de métodos disponibles para el análisis de la política internacional. Del otro, se propone un marco de comprensión de las decisiones de unos actores que, en caso de las realidades objetivas en las que este se basa se mantengan, puede servir para comprender los efectos de su liderazgo en el ámbito internacional.

De hecho - y esto es algo que tampoco se ha hecho de manera extensa, por lo menos en América Latina- este escrito no se concentró en analizar cuáles son las posibilidades reales de estos países de convertirse en países potencia; en poderes internacionales. No solo en el largo plazo, sino en remplazo de Estados Unidos. En este escrito se asumió que ya lo son y la mayoría de reflexiones sobre el tema reúnen criterios específicos que aportan evidencia a que son potencias en ascenso o que aún no pueden asumirse como tales. 
Pero son muy pocos, casi inexistentes, los que reflexionen sobre la posibilidad real de ser potencias. Tampoco se ha profundizado en observar si ese ascenso significaría una alternativa real a las lógicas del sistema internacional, tradicionalmente liderado por países occidentales, desarrollados. O sus implicaciones.

Otro aspecto que se busca rescatar es la necesidad de que el análisis, por lo menos el académico, reconozca la diferencia entre lo que se plantea en el discurso y lo que implican las acciones/decisiones de los actores. Muchos ejemplos de esta necesaria distinción se encuentran aquí. No porque se afirme que se será más incluyente se puede asumir, sin mirar nada más, que así lo será. Con esto no se pretende afirmar que los países BRICS busquen esconder sus verdaderas intenciones detrás de un discurso basado en la paz y la cooperación. Eso no se puede saber. Lo que sí se puede hacer es interpretar ese discurso a la luz de los hechos que se encuentran en las prácticas o acciones de los actores.

Un elemento en el que no se profundizó es en las lógicas del poder. En el caso de Estados Unidos y del Reino Unido, este se basó en los procesos de desarrollo de ambos países. En el caso de los BRICS, como se señaló en su momento, se ha fundamentado principalmente en la percepción que los demás tienen de estos países y que estos buscan proyectar. ¿Se está ante un nuevo poder? ¿De qué tipo de poder se está hablando? ¿Es viable? ¿Es estable?

De igual manera, no se ahondó en la cuestión sobre si el poder, luego de adquirido, desencadena algunas lógicas de comportamiento que hace que, en el largo plazo, todos los países potencia se comporten de la misma manera. Si esto se demostrara, tendría que asumirse que el discurso de los países BRICS corresponde a la etapa del poder en la que se encuentran, lo cual no quiere decir que un sistema internacional liderado por ellos vaya a ser muy diferente en el largo plazo.

Un último aspecto sobre el que se hubiera podido reflexionar es el relacionado con la cooperación. En el escrito se mostraron, principalmente, las dificultades para establecer cooperación entre cinco países. Pero, como se afirmó más arriba, esos aspectos pueden cambiar. En 
caso de ser posible la cooperación no quiere decir, sin embargo, que esto sea positivo en ninguno de los aspectos analizados.

Puede que los países BRICS cooperen para, por ejemplo, adelantar estrategias de engaño y manipulación global o de saqueo internacional. Esto sería cooperación, pero no una deseable para el resto del mundo. Es necesario también darle contenido al concepto de cooperación para evaluar sus impactos e implicaciones, algo que no se ha hecho y que en este escrito no se cubrió.

Existe principalmente incertidumbre en el análisis de las implicaciones de un ascenso global de los países BRICS. Acá se mostraron todos los elementos que generan dudas sobre tal fenómeno. Pero también se señaló que muchos de los supuestos que derivan esos elementos pueden cambiar. Sin embargo, los cambios no se generan exógenamente sino, como algunos han demostrado (Sprinz, D. F. \& Wolinsky-Nahmias, 2007, p. 346; Jervis, 1976) de manera endógena: si cambian las ideas o los mitos sobre los cuáles se construyen las percepciones de los actores. Esto depende de un proceso constante de retroalimentación y de reflexión sobre las razones ideológicas (esto es, resultado de las ideas) que generen una diferencia entre los fines buscados y los medios utilizados. ¿Estos procesos de reconocimiento de los problemas ideológicos se adelantarán en los países BRICs? Aún no se ha hecho. No existe evidencia de que comience pronto. Pero esta también es otra incertidumbre.

\section{Referencias}

Audard, C. (2009). Qu'est-ce que le libéralisme? Éthique, politique, société. París: Folio Essais.

Avant, D. D., Finnemore, M. \& Sell, S.K. (Eds.). (2010). Who governs the globe? Cambridge: Cambridge Univerity Press.

Axelrod, R. (2006). The evolution of cooperation. Nueva York: Basic Books.

Brawley, M. R. (2007). Bulding blocks or a BRIC wall? Fitting U.S. foreign policy to the shifting distribution of power. Asian Perspective, 31(4), 151-175. 
Chen, Z. (2015). China's dangerous debt. Why the economy could be headed for trouble. Foreign Affairs, 94(3), 13-18.

Fearon, J. D. (1995). Rationalist explanations for war. International Organization, 49, 379-414.

Finnemore, M. \& Goldstein, J. (Eds.). (2013). Back to the basics: State power in a contemporary world. Oxford: Oxford University Press.

Flemes, D. (2013). Network powers: Strategies of change in the multipolar system. Third World Quarterly, 34(6), 1016-1036.

Herz, J. H. (1950). Idealist internationalism and the security dilemma. World Politics, 2(2), 157-180.

Ikenberry, G. J. (2011). Liberal Leviathan: The origins, crisis, and transformation of the American system. Princeton: Princeton University Press.

Jehle, G. A. \& Reny, P. J. (2001). Advanced microeconomic theory. Nueva York: Addison Wesley.

Jervis, R. (1976). Perception and misperception in international politics. Princeton: Princeton University Press.

Jervis, R. (1978). Cooperation under the security dilemma. World Politics, 30, 167-214.

Katzenstein, P. (2013). States and power as UR-force: Domestic traditions and embedded actors in world politics. En M. Finnemore \& J. Goldstein (Eds.), Back to the basics: State power in a contemporary world (pp. 139157). Oxford: Oxford University Press.

Kissinger, H. (2014). World order. Reflections on the Character of Nations and the Course of History. Estados Unidos: Penguin.

Lake. D. (2013). Authority, coercion, and power in international relations. En M. Finnemore \& J. Goldstein (Eds.), Back to the basics: State power in a contemporary world (pp. 55-77). Oxford: Oxford University Press.

Leung, J. (2015). Xi's corruption crackdown. How bribery and graft threaten the Chinese dream. Foreign Affairs, 94(3), 32-38.

Magee, S., Brock, W. \& Young, L. (1989). Black ole tariffs and endogenous policy theory. Cambridge: Cambridge University Press.

Mielniczuk, F. (2013). BRICS in the contemporary world: Changing identitites, converging interests. Third World Quarterly, 34(6), 1075-1090.

Morrow, J. D. (1989). Capabilities, uncertainty, and resolve: A limited information model of crisis bargaining. American Journal of Political Science, 33(4), 941-972. 
North, D. \& Thomas, R. (1973). The rise of the western world. Cambridge: Cambridge University Press.

Nozick, R. (1977). Anarchy, state, and utopia. Nueva York: Basic Books.

Ostrom, E. (1990). Governing the commons. Cambridge: Cambridge University Press.

Oye, K. A. (1986). Cooperation under anarchy. Princeton: Princeton University Press.

Pahre, R. (1999). Leading questions: How hegemony affects the international political economy. Chicago: University of Chicago Press.

Pew Research Center. (2015). Global indicators database. Recuperado de http:/ / www.pewglobal.org/database/

Powell, R. (1990). Nuclear deterrence theory: The problem of credibility. Cambridge: Cambridge University Press.

Putnam, R. D. (1988). Diplomacy and domestic politics. International Organization, 42(3), 427-460.

Rawls, J. (1999). A theory of justice. Boston: Harvard University Press.

Rogowski, R. (1989). Commerce and coalitions. Princeton: Princeton University Press.

Ruggie, J. G. (1992). Multilateralism: the anatomy of an institution. International Organization, 46(3), 561-598.

Ruggie, J. G. (1982). International regimes, transactions, and change: Embedded liberalism in the postwar economic order. International Organization, 36(2), 379-415.

Sprinz, D. F. \& Wolinsky-Nahmias, Y. (Eds.). (2007). Models, numbers \& cases: Methods for studying international relations. Chicago: University of Michigan Press.

Stein, A. (2013). Power Politics and the Powerless. En M. Finnemore \& J. Goldstein (Eds.), Back to the basics: State power in a contemporary world (pp. 219-248). Oxford: Oxford University Press.

Szilagyi, M. N. (2003). An investigation of n-person prisoner's dilemmas. Complex Systems, (14), 155-174.

Vlad, L. B., Hurduzeu, G., Joseun, A. \& Vlăsceanu, G. (2011). The rise of BRIC, the 21st century geopolitics and the future of the consumer society. Romanian Review on Political Geography, 13(1), 48-62.

Waltz, K. (1979). Theory of international politics. Reading, Massachusetts: Addison-Wesley. 
Wendt, A. (1999). Social theory of internationalpolitics. Cambridge: Cambridge University Press.

Youwei. (2015). The end of reform in China. Authoritarian adaptation hits a wall. Foreign Affairs, 94(3), 2-7.

Yuequin, L. (2010). The rise of emerging powers and the BRICs' chase to catch up. Chinese Economist, (25), 66-73. 